\title{
Liberalismo autoritário: Carl Schmitt e Hermann Heller encontram Wendy Brown ${ }^{1}$
}

\section{Authoritarian liberalism: Carl Schmitt and Hermann Heller meet Wendy Brown}

\author{
Juliana Fonseca Pontes ${ }^{2}$ \\ Instituto Brasiliense de Direito Público (Brasília, DF, Brasil) \\ ORCID: https://orcid.org/0000-0001-7551-0855 \\ E-mail: jufpontes1@gmail.com
}

\begin{abstract}
Loiane Prado Verbicaro ${ }^{3}$
Universidade Federal do Pará (Belém, PA, Brasil) ORCID: https://orcid.org/0000-0002-3259-9906

E-mail: loianeverbicaro@uol.com.br
\end{abstract}

\section{Resuimo}

$\mathrm{O}$ artigo se propõe a investigar o fenômeno do "liberalismo autoritário" a partir do debate travado entre os juristas alemães Carl Schmitt e Hermann Heller, no contexto da República de Weimar, e da análise a respeito do neoliberalismo elaborada pela filósofa e cientista política contemporânea Wendy Brown, no livro Nas Ruínas do Neoliberalismo (2019). O objetivo é identificar em que medida os argumentos levantados pela autora se aproximam da discussão entre os juristas e se a experiência alemã é capaz de oferecer algumas interlocuções com o atual modelo neoliberal. O artigo foi desenvolvido a partir de pesquisa bibliográfica, abordada a partir do método dedutivo e de análise crítico-interpretativa.

\footnotetext{
${ }^{1}$ PONTES, Juliana Fonseca; VERBICARO, Loiane Prado. Liberalismo autoritário: Carl Schmitt e Hermann Heller encontram Wendy Brown. Suprema: revista de estudos constitucionais, Brasília, v. 1, n. 1, p. 404-426, jan./jun. 2021.

${ }^{2}$ Pós-graduanda em Direito Constitucional pelo Instituto Brasiliense de Direito Público (IDP). Bacharel em Direito pelo Centro Universitário do Pará (CESUPA). Integrante do Grupo de Pesquisa CNPq: Filosofia Prática: Investigações em Política, Ética e Direito, vinculado à Faculdade de Filosofia da Universidade Federal do Pará (UFPA). Integrante da Liga Acadêmica de Direito do Estado (LADE). Autora na Revista Estado da Arte (vinculada ao jornal O Estado de São Paulo). Assessora Jurídica na Procuradoria Geral do Estado do Pará (PGE-PA). Currículo Lattes: https://lattes.cnpq.br/2941229677884603.

${ }^{3}$ Doutora em Filosofia do Direito pela Universidade de Salamanca (USAL). Professora do Programa de Pós-Graduação em Filosofia (PPGFIL) e do Programa de Pós-Graduação em Direito e Desenvolvimento da Amazônia (PPGDDA), ambos vinculados à Universidade Federal do Pará (UFPA). Mestra em Direitos Fundamentais e Relações Sociais pela UFPA. Mestra em Ciência Política pela UFPA. Graduada em Direito pela - suma cum laude - UFPA. Graduada em Filosofia (Bacharelado) pela UFPA. Realiza Estágio Pós-Doutoral no Departamento de Filosofia do Direito da Universidade de São Paulo (USP). Líder do Grupo de Pesquisa - CNPq: Filosofia Prática: Investigações em Política, Ética e Direito. Autora do livro "Judicialização da Política, Ativismo e Discricionariedade Judicial”. Editora-Chefe da Revista Apoena - Periódico de Filosofia da Universidade Federal do Pará. Integrante da Rede Brasileira de Mulheres Filósofas. Integrante do GT Filosofia e Gênero da Associação Nacional de PósGraduação em Filosofia - ANPOF. Currículo Lattes: https://lattes.cnpq.br/4100200759767576.
} 


\section{Palavras-chave}

República de Weimar; neoliberalismo; autoritarismo; liberalismo.

\section{Sumário}

1. Introdução. 2. O debate entre Carl Schmitt e Hermann Heller. 3. A leitura de Wendy Brown sobre o paradigma neoliberal. 4. Os impasses de Weimar e os impasses atuais. 5. Conclusão.

\section{Abstract}

The article aims to investigate the "authoritarian liberalism" phenomenon by examining the debate between the German jurists Carl Schmitt and Hermann Heller, in the context of the Weimar Republic, and the recent analysis of neoliberalism made by the contemporary American philosopher Wendy Brown in the book Nas Ruinas do Neoliberalismo (2019). The goal is to identify the extent to which the arguments presented by the author are close from the discussion between the jurists and whether the German experience is capable of clarifying some particularities of the current neoliberal paradigm. The article was developed through bibliographic research, analyzed from the deductive method and critical-interpretative analysis.

\section{Keywords}

Weimar Republic; neoliberalism; authoritarianism; liberalism.

\section{Contents}

1. Introduction. 2. The debate between Carl Schmitt and Hermann Heller. 3. Wendy Brown's reading on the neoliberalism paradigma. 4. Weimar's impasses and current impasses. 5. Conclusion. 


\section{Introdução}

Carl Schmitt (1888-1985) foi um dos mais influentes juristas iliberais da história das ideias. Tendo publicado grande parte de sua obra durante a chamada República de Weimar (1919-1933) na Alemanha, elaborou um sofisticado arcabouço teórico que serviu à capitulação do sistema político e jurídico inaugurado pela vanguardista Constituição de Weimar e à legitimação do regime nazifascista de Adolf Hitler.

Hermann Heller (1891-1933), por sua vez, foi um jurista weimariano que, na contramão, promoveu uma defesa inarredável do recém-inaugurado regime democrático e do sistema de direitos individuais e sociais previstos pela nova Constituição. Com tendências políticas alinhadas ao socialismo democrático, Heller fez oposição vocal a Schmitt e, no que se refere à relação entre liberalismo econômico e autoritarismo, engendrou com ele um dos debates mais profícuos do século XX.

Esse debate será objeto de análise neste artigo, que investigará a possibilidade de, a partir dele, refletir-se acerca de eventuais aproximações com as discussões contemporâneas sobre o neoliberalismo e sua racionalidade antidemocrática. Para tanto, na última seção do artigo, recorreremos ao estudo sobre o neoliberalismo e a aliança que promove entre autoritarismo e liberalismo econômico realizado pela filósofa e cientista política norte-americana Wendy Brown, para avaliarmos se, e em que medida, suas considerações podem ser enriquecidas pelo debate dos juristas alemães travado durante a experiência-limite da República de Weimar.

Partiremos da obra do alemão Carl Schmitt, o jurista emérito do III Reich, e nos debruçamos, com especial atenção, sobre o discurso que proferiu em 1932 a uma associação de industriais de Düsseldorf intitulado Estado forte e economia saudável (Starker Staat und gesunde Wirtschaft). Às vésperas da declaração de estado de exceção por Adolf Hitler, Schmitt dirigiu ao empresariado alemão a mensagem de que a Constituição de Weimar, liberal e democrática, havia criado um Estado fraco porquanto cheio de obrigações (a exemplo das prestações relativas a direitos fundamentais sociais), permanentemente em disputa (como consequência da democracia deliberativa) e que ameaçava o livre mercado com instrumentos econômicos socialistas (em razão de sua tentativa de implementar uma democracia econômica). A este Estado, Schmitt chamou de Estado Total Quantitativo ${ }^{4}$.

Em substituição, propôs o advento de um Estado Total Qualitativo (leia-se, autoritário): um Estado que garantisse o laissez-faire e se abstivesse de intervenções

${ }^{4}$ Cf. Bercovici (2003). 
no domínio econômico, mas que fosse fortemente militarizado e centralizado. Seu propósito era promover a despolitização das esferas não estatais e restabelecer ao Estado o monopólio do político, nos moldes do argumento que apresenta em $O$ conceito do político (Der Begriff des Politschen, 1932), para garantir que a economia fosse uma instância privada e autônoma, enquanto coubesse exclusivamente ao soberano a distinção entre amigos e inimigos. A bem da verdade, Schmitt pretendia pôr a salvo os interesses das classes dominantes das transformações que a democracia e o Estado social poderiam promover (BERCOVICI, 2003, p. 89).

Em um segundo momento, analisaremos o contraponto oferecido por Hermann Heller ao posicionamento de seu par. Às ideias defendidas por Schmitt no referido discurso, o constitucionalista, seu contemporâneo e grande antagonista, respondeu no artigo Liberalismo Autoritário? (Autoritärer Liberalismus?, 1933). Segundo Heller, aqueles que clamavam por autoritarismo naquela altura eram os mesmos círculos econômicos e militares que, desde 1918, tentavam minar a autoridade democrática do Estado e a eficácia da nova Constituição. Denunciou que a requerida retirada do Estado da economia era relativa tão somente à implementação de políticas sociais e que não almejava a cassação dos privilégios já concedidos à classe capitalista, mas antes o contrário: era para a manutenção desses privilégios que se fazia necessário o autoritarismo do Estado.

É importante lembrar que a Constituição de Weimar promoveu a participação das classes trabalhadoras no Parlamento, o que então ameaçava a conservação das desigualdades. A esse respeito, Gilberto Bercovici explica que, não havendo como excluir o proletariado do Poder Legislativo pelo Estado de Direito, a burguesia passou a renegar este último e a buscar soluções ditatoriais que assegurassem seu predomínio político (BERCOVICI, 2003, p. 108). Diante da tentativa coordenada de desmantelamento do sistema de garantias constitucionais e de agravamento da precarização de relações econômicas, Heller arrematou: o Estado Neoliberal (neoliberalen Staat) teria mesmo que ser autoritário, porque o povo alemão jamais o sustentaria democraticamente (HELLER, 2015, p. 301)

Um dos alertas mais prementes feitos por Heller foi o de que o regime democrático garantido pela Constituição de Weimar estava sendo ameaçado por forças econômicas insatisfeitas com os instrumentos de justiça social recém-inventados: a relação conflituosa (e muitas vezes insidiosa) entre capitalismo e democracia foi por ele reconhecida e analisada. Wendy Brown, em Nas Ruinas do Neoliberalismo (In the ruins of neoliberalism, 2019), parece ter feito o mesmo esforço, ainda que em distinto contexto, tempo histórico e marco teórico. 
No livro, Brown demonstra como, depois da Segunda Guerra Mundial, os intelectuais neoliberais se esforçaram para redesenhar as estruturas do Estado a partir da dinâmica econômica, de modo a favorecer os interesses das classes capitalistas dominantes. Para eles, toda forma de intervenção do Estado em assuntos econômicos e sociais é sinônimo de opressão e se opõem, de maneira geral, à legislação trabalhista protetiva, aos direitos sociais e à atividade sindical engajada - precisamente os alvos prediletos do empresariado durante da República de Weimar.

Em razão dessas aproximações, investigaremos se o debate entre Carl Schmitt e Hermann Heller pode contribuir para a compreensão da dinâmica política e econômica do neoliberalismo contemporâneo tal como analisada pela filósofa Wendy Brown.

$\mathrm{O}$ artigo foi realizado a partir de pesquisa bibliográfica, abordada com base no método dedutivo e de análise crítico-interpretativa. Sua importância se justifica pela urgência de estudos sobre os processos que podem levar à derrocada das democracias contemporâneas, bem como à fragilidade de sistemas de direitos e de instrumentos de distribuição de riquezas em sociedade. O desmantelamento do Estado Social e a intensificação de discursos violentos, virulentos e segregacionistas são fenômenos que merecem refinada reflexão que auxilie a lançar luzes sobre o advento de políticas antidemocráticas que têm se concretizado a partir de regimes híbridos: democrático-autocráticos.

\section{O debate entre Carl Schmitt e Hermann Heller}

Como assevera Heiner Bielefeldt, Carl Schmitt não integra a tradição de críticos do liberalismo que, em alguma medida, reconhecem como positivos alguns de seus feitos: diferentemente, o alemão atacou de modo implacável a rule of law, as instituições liberais e o arranjo liberal entre direito e poder com o objetivo de vê-los substituídos por uma alternativa autoritária (BIELEFELDT, 1998, p. 24).

E a Constituição de Weimar foi seu alvo imediato ${ }^{5}$. Elaborada a partir de um anteprojeto do jurista liberal de esquerda Hugo Preuss, com a colaboração de Max Weber, foi a primeira Constituição europeia a conceder status constitucional a direitos sociais, a reconhecer a liberdade de organização sindical como direito fundamental e a dedicar um capítulo inteiro à organização da vida econômica do país, de modo a torná-la uma questão política ${ }^{6}$. Como assevera Gilberto Bercovici (2003, p. 11-12),

\footnotetext{
${ }^{5}$ Cf. Bueno (2017); Mouffe (1999); Seitzer (1998).
}

${ }^{6}$ A Constituição de Weimar é entendida como uma constituição econômica por ter consagrado uma série de instrumentos por meio 
não era uma Constituição homogênea, mas uma expressão do pluralismo de forças em disputa em 1919 e tinha o compromisso politicamente aberto de promover uma renovação democrática na Alemanha. Por isso, é considerada uma Constituição compromissária ou programática (Verfassungkompromiss).

Carl Schmitt foi um de seus maiores detratores ${ }^{7}$. Em texto intitulado $A$ crise da democracia parlamentar (Die geistesgeschichtliche Lage des heutigen Parlamentarismus, 1923), o jurista teceu duras críticas ao regime parlamentar instaurado na Alemanha pela novel Constituição. Para ele, o parlamentarismo é um modo de organizar o poder próprio do liberalismo, que é incompatível com a essência da democracia: liberalismo e democracia são, para Schmitt, inconciliáveis (SCHMITT, 1996a, p. 16).

Isso porque o liberalismo, argumenta o alemão, encontra seu fundamento na aplicação do princípio da igualdade em termos formais à generalidade, de modo que todos os cidadãos são tomados como abstratamente iguais perante a lei. Como consequência obrigatória, todas as ideias, valores, opiniões e visões de mundo possivelmente esposadas pelos cidadãos têm lugar legítimo nos espaços de poder notadamente no Parlamento -, o que tornaria as sociedades liberais necessariamente plurais. Enquanto o Estado é agnóstico, laico e neutro, a sociedade é heterogênea.

No entanto, a democracia exigiria homogeneidade: para Schmitt, um país só pode se considerar democrático se há identidade entre governantes e governados, entre os que mandam e os que obedecem - e essa identidade só é possível quando o povo é relativamente homogêneo. Schmitt argumenta ainda que, quando assim não se constitui, é uma prerrogativa do soberano assim torná-lo: "portanto, a democracia deve, em primeiro lugar, ter homogeneidade e em segundo - se for preciso - eliminar ou aniquilar o heterogêneo”. (SCHMITT, 1996, p. 10). Assim sendo, é forçoso concluir que sua teoria da democracia requer a exclusão e é potencialmente violenta (PREUSS, 1999, p. 171).

Seguindo este raciocínio, o jurista caracteriza o Parlamento como uma “instituição obsoleta e inconcebível”, na medida em que o princípio da igualdade, fundamento do sistema liberal parlamentarista, seria incompatível com o da homogeneidade, exigido pela democracia (SCHMITT, 1996a, p. 16). Contudo, essa incompatibilidade não se verificaria com relação aos regimes autocráticos. Schmitt 
aduz que "qualquer ditadura, o bolchevismo e o fascismo são antiliberais, mas não são antidemocráticos" e adiciona que, "na história da democracia, existem algumas ditaduras, imperialismos e outros exemplos gritantes de educação da vontade do povo, para a obtenção da homogeneidade." (SCHMITT, 1996a, p. 16). Democracia, no sentido schmittiano, significa a expressão política irrestrita da identidade de um povo específico (BIELEFELDT, 1998, p. 27), de modo que não apresenta qualquer inadequação virtual com a tirania ${ }^{8}$.

Esses argumentos são confirmados e elaborados mais detidamente em uma de suas obras de maior relevo, Teoria da Constituição (Verfassunglehre, 1928). Nesse texto, o jurista defende que a igualdade possível em regimes democráticos é uma de tipo substancial, ou seja, uma igualdade afirmada a partir de algum critério objetivo e material, definida a partir de categorias como ideias de raça, fé comum, de destino e tradição comuns, de modo que o povo possa ser definido como um corpo homogêneo e, assim, se diferenciar de outros povos - em especial dos povos inimigos (SCHMITT, 1996b, p. 224-225). Seu raciocínio pode ser assim resumido:

Somente quando há uma homogeneidade substancial, um parentesco efetivo, como, por exemplo, em Estados com uma população nacional homogênea orientada na mesma direção, é razoavelmente possível considerar excluída de modo permanente, a despeito das eventualidades, uma inimizade (SCHMITT, 1996b, p. 358).

Nessa direção, Schmitt escreve que, "nas democracias, só existem a igualdade dos iguais e a vontade daqueles que pertencem aos iguais" (SCHMITT, 1996a, p. 16) - e esses “iguais” são distinguidos pelo Estado em contraposição aos diferentesinimigos. Quando a homogeneidade substancial do povo é ameaçada pelas divisões do pluralismo, o Estado deveria reafirmar sua unidade apontando inimigos, de modo a promover coesão social: uma vez que a distinção entre amigos e inimigos é realizada, tensões internas são apaziguadas (LEYDET, 1998, p. 116).

Em poucas palavras, a teoria da democracia schmittiana é iliberal, compatível com o fascismo e, para que se sustente, exige o extermínio do “diferente" pelo Estado. Além disso, vê no pluralismo e na heterogeneidade da sociedade sinal de fraqueza política estatal e defende a afirmação da identidade do povo na sua oposição polêmica a outros agrupamentos sociais tomados como inimigos.

\footnotetext{
${ }^{8}$ A esse respeito, ensinam Erbel e Salomon: "Segundo Schmitt, o princípio da maioria e, com ele, a identificação entre legitimidade e legalidade só poderia ser confirmado pela premissa de que 'em virtude do mesmo pertencimento ao mesmo povo todos querem essencialmente a mesma coisa da mesma maneira'. A partir do momento em que essa condição não se verifica, 'leva-se a si mesmo ad absurdum"' (2019, p. 756-757).
} 
Em O guardião da Constituição (Der Hüter der Verfassung, 1931), Schmitt dá alguns passos além. Naquela oportunidade, explicou que, no século XIX, o Estado Moderno se afirmou em oposição à sociedade e se constituiu como uma esfera neutra, acima das divergências existentes, em especial religiosas, guardando o monopólio sobre matérias essencialmente políticas - para ele, sempre referentes à distinção militar entre amigos e inimigos (SCHMITT, 2007, p 107). ${ }^{9}$

Anteriormente, a "sociedade" era precisamente aquilo que não constituía o Estado, de modo que este último podia ser diferenciado da primeira com facilidade e era "forte o suficiente para se opor autonomamente às demais forças sociais" (SCHMITT, 2007, p. 108). Era possível determinar, a partir de e em oposição ao Estado, a sociedade com seus inúmeros agrupamentos de numerosas diversidades.

No entanto, com a consolidação do Estado Liberal burguês, a diferenciação entre Estado e sociedade teria se tornado cada vez mais difícil, na medida em que os cidadãos passaram a "participar" do Estado, a ocupá-lo por dentro, notadamente por meio de organismos de poder como o Parlamento (SCHMITT, 2007, p. 108). Pergunta o jurista: "como avaliar o Estado e a sociedade, se eles se opõem reciprocamente e são dependentes entre si?" (SCHMITT, 2007, p. 108).

A dinâmica dualista Estado-sociedade teria desaparecido, e o Estado, agora organizado pela segunda, interviria em todos os assuntos da vida social, porquanto todos os problemas sociais e econômicos teriam se convertido em problemas políticos (SCHMITT, 2007, p. 115). Gilberto Bercovici explica que, para o autor, o Estado Total é um Estado invadido pelas mais diversas reivindicações e que sofre pressão de todos os grupos políticos existentes na sociedade. Por isso, é um Estado fraco, sob constante ameaça de fragmentação: deixa de ser soberano e passa a ser um "complexo crescente de órgãos públicos mal coordenados" (BERCOVICI, 2003, p. 81). Na lição de Argemiro Martins, "as instâncias sociais neutralizadas pelo liberalismo, tais como a economia, a religião, a ciência e o direito são politizadas a ponto de romperem a estabilização liberal embasada sobre a "área central" da ética e da economia”. (MARTINS, 1996, p. 72)

Schmitt argumenta que esse fenômeno é parte de um desenvolvimento dialético, de uma evolução política que decorreria em três estágios: a transição do Estado absolutista dos séculos XVII e XVIII para o Estado neutro do liberalismo do século XIX, até finalmente a sua transformação em Estado total, caracterizado pela identidade entre Estado e sociedade (SCHMITT, 2007, p. 119). E a esfera econômica seria parte central nesse processo. 
A economia financeira pública teria sofrido alterações quantitativas e qualitativas, sido alvo de uma "mudança estrutural" que alcançaria todas as esferas da vida pública: o aumento do tamanho do Estado. A título de ilustração, o autor menciona o dado, calculado para o ano de 1928 , de que $53 \%$ da receita nacional alemã eram então controlados pelo poder público e afirma que nem seria necessário investigar se tal informação estava mesmo correta, porque o fenômeno do agigantamento do Estado, notadamente na economia, seria "incontestável e incontroverso" (SCHMITT, 2007, p. 119). Estar-se-ia diante do advento do "Estado total".

O que Schmitt chama de Estado total é simplesmente o Estado Social erigido pela Constituição de Weimar, que garantia uma série de direitos econômicos e sociais e intervinha na economia para minimizar os efeitos da crise pós-Primeira Guerra Mundial. Nesse sentido, para Schmitt, o Estado total era tanto o resultado das contradições do liberalismo clássico, como também a resposta natural às condições econômicas da época (SCHEUERMAN, 2020, p. 103).

A esse respeito, no ano seguinte, em uma conferência concedida ao empresariado industrial em Düsseldorf intitulada Estado forte e economia saudável (Starker Staat und gesunde Wirtschaft, 1932), Schmitt (1995, p. 73-74) fez uma distinção teórica importante. Asseverou que o Estado alemão, subordinado à Constituição de Weimar, era um Estado Total Quantitativo e que a solução ótima era que se tornasse um Estado Total Qualitativo. Este último teria condições de exercer de modo exclusivo e indisputado o monopólio político, vale dizer, seria capaz de realizar a distinção entre amigos e inimigos, e de exercer seu domínio sobre a sociedade acima e para além das disputas de interesses econômicos, notadamente entre aqueles conflitantes, dos trabalhadores e dos empresários. Schmitt vê no Estado Fascista de Mussolini um exemplo de Estado dessa natureza. (SCHMITT, 1995, p. 73).

No que se refere à economia, o Estado Total Qualitativo subordinaria a esfera privada ao seu domínio, mas garantiria sua liberdade: embora permanecesse autônoma, as disputas sociais de fundo econômico seriam neutralizadas (SCHMITT, 1995, p. 7374). É nesse ponto que reside a relevância de nossa remissão à obra schmittiana: para o jurista, o Estado deve ser forte e a economia, livre. Em outras palavras, Schmitt era favorável a um governo autoritário que conseguisse garantir liberdade econômica ao grande capital. A tentativa de isolar a economia da influência política de órgãos de representação popular buscava blindar os interesses das classes empresariais que se encontravam ameaçadas não só pela crise econômica, mas também pela atuação parlamentar das classes proletárias (BERCOVICI, 2003, p. 66). ${ }^{10}$

\footnotetext{
${ }^{10}$ A esse respeito, assevera António José Avelãs Nunes: "Naquelas condições históricas (da história do capitalismo na sua fase
} 
Schmitt foi um opositor inveterado do liberalismo político, mas foi um defensor do liberalismo econômico. Como conclui Bercovici, a proposta econômica schmittiana busca liberar o capital do Estado Social, de modo que, nas palavras de Ingeborg Maus, Schmitt se coloca contra o status quo político e jurídico da República de Weimar, mas é favorável ao seu status quo econômico. A intenção de despolitizar a economia tinha como objetivo proteger os interesses das classes mais abastadas da democracia pluralista, das limitações do Estado Social e dos direitos sociais previstos pela Constituição (BERCOVICI, 2003, p. 89).

Desse modo, Schmitt parece aliar autoritarismo político e livre mercado: aliança insidiosa que foi percebida e criticada por seu contemporâneo, o jurista Hermann Heller ${ }^{11}$, em um artigo intitulado Liberalismo Autoritário? (Autoritärer Liberalismus?, 1933).

O texto inicia afirmando que a expressão "Estado autoritário" era a palavra de ordem na Alemanha naquele momento e que um estrangeiro pouco familiarizado com as questões alemãs com certeza não estaria em posição de reconhecer as intenções políticas concretas que animavam aquela utilização. Por essa razão, o jurista passa a tentar explicar exatamente o que significava (HELLER, 2015, p. 295).

Estado autoritário, escreve Heller, é um conceito que se opõe ao de Estado democrático. A sua exortação na República de Weimar é resultado do fato de os alemães terem rompido irremediavelmente a unidade entre lei e poder, de modo que os social-democratas estavam reivindicando para si, acima de tudo, a lei e não sabiam como fazer bom uso do poder, com o qual seus inimigos, entretanto, se acomodaram cada vez mais confortavelmente (HELLER, 2015, p. 296).

O discurso favorável ao autoritarismo estaria ganhando a adesão do povo alemão também por causa de fraquezas próprias do regime democrático. Heller (2015, p. 296) escreve que, em meio à profunda crise econômica e política enfrentada no país e à decretação de sucessivos estados de exceção pelos gabinetes presidenciais, a simpatia pela ideia de uma autoridade forte e centralizadora que pudesse estabilizar os conflitos e operar os "milagres" de uma ditadura encontrou solo fértil. O jurista afirma que, "em um estado de exceção repleto de crise, uma concepção de Estado que - como a de Carl Schmitt - declara regras e normas como insignificantes e a exceção como decisiva pode ter sucesso" e que "por um ano e meio, essa concepção tentou rebaixar a autoridade democrática em favor da autoridade ditatorial do Estado” (HELLER, 2015, p. 296). 
Heller (2015, p. 296-297) critica a concepção de Carl Schmitt sobre ditaduras e regimes excepcionais, afirmando que, desde as antigas democracias romanas, reconheceu-se que, em situações de emergência, os estados de exceção podem ser necessários: torna-se premente a concentração da autoridade do Estado nas mãos de um sujeito eleito democraticamente, que pode ser revogada assim que cessa a ocasião de perigo. Mas Schmitt, diz Heller, com base em uma lógica que considera audaciosa, apresenta o estado de exceção como o status verdadeiro do Estado e advoga por uma ditadura autocrática permanente, sem qualquer relação com as situações de emergência, alegando ser esse regime uma verdadeira democracia.

Essa compreensão enviesada da exceção explicaria por que a doutrina jurídica schmittiana entende a Constituição não como um sistema de normas, mas como uma decisão; o parlamentarismo como uma instituição sem sentido que tem como objetivo o alcance das verdades eternas por meio da discussão; e considera qualquer forma de adjudicação de matérias constitucionais um veneno projetado para retroceder o Império Alemão ao estado de impotência em que se encontrava nos séculos XVII e XVIII (HELLER, 2015, p. 296).

Heller (2015, p. 298) segue e avalia que o fundamento ideológico do socialismo e do nacional-socialismo völkisch repousa na crença que um povo culturalmente homogêneo pode ser criado por meio de uma comunidade econômica autoritária ou de uma comunidade racial autoritária. Quem estava convencido de que era necessário um corpo racial comum exigiria do Estado a criação de uma comunidade cultural por meios raciais. Grandes círculos da população alemã daquela época estariam chamando essa perspectiva de "idealista”. Em contraste, as classes mais abastadas e educadas entenderiam como "materialista" a crença de que uma comunidade espiritual poderia ser fabricada por meio de uma comunidade econômica autoritária (HELLER, 2015, p. 298).

O jurista considera que um Estado autoritário com fundamentação racial não era uma ideia tomada seriamente pelos conservadores - algo que podemos apontar, escrevendo depois da ascensão e da queda do III Reich, como uma avaliação equivocada. $\mathrm{O}$ que seria decisivo naquele momento, segundo Heller, para o caráter político e social do Estado autoritário, era sua visão da forma capitalista da economia (HELLER, 2015, p. 298).

No século XIX, o conservadorismo prussiano teria rejeitado veementemente o capitalismo liberal burguês que dissolveu os laços sociais recebidos (HELLER, 2015, p. 299). Entretanto, sem estar em condições de impedir o desenvolvimento dessa forma econômica, o conservadorismo ainda possuía força para inculcar na burguesia liberal 
suas sensibilidades políticas e, assim, gradualmente torná-la feudal. Heller considera que o produto desse cruzamento feudal-capitalista tão específico foi o que chamou de "liberalismo nacional". Com o advento do século XX, no entanto, esse processo teria sofrido uma inversão. O capitalismo burguês de classe alta teria demonstrado maior força de assimilação, e o conservadorismo foi "drenado de sua última gota de óleo social”. Correspondendo a essa transformação sociológica, Heller considera que o Estado autoritário representa um desenvolvimento consistente do então chamado liberalismo nacional, que, então conclui, "mais apropriadamente deve ser tratado como liberalismo autoritário” (HELLER, 2015, p. 299). ${ }^{12}$

Heller (2015, p. 300) avalia que o Estado autoritário é alternativa política escolhida pelo liberalismo, que é liberal tão somente em matérias econômicas: quando se trata de economia, o autoritarismo do Estado desaparece completamente. Os conservadores, que se animavam com a ideia de um Estado autoritário, defendiam, com o mesmo entusiasmo, uma retirada desse Estado da economia, para que o âmbito estatal e o econômico fossem radicalmente separados.

Um dos conservadores que integravam esse grupo, escreve Heller (2015, p. 299), era precisamente Carl Schmitt. Este último finalmente teria entendido ter "chegado a hora" de expressar suas ideias sobre o Estado autoritário com mais clareza - ideias essas que teriam sido escondidas durante muito tempo por trás de um vocabulário sofisticado (HELLER, 2015, p. 299). Essa hora a que Heller se refere é a ocasião do discurso Estado forte, economia saudável, proferido a industriais de Düsseldorf, mencionado neste artigo anteriormente.

A excitação gerada pela liberalização (Entstaatlichung) da economia, pelo delineamento de uma esfera econômica sem Estado, não deve teve ter sido facilmente explicável para Schmitt, o teórico do Estado autoritário total. Até aquele momento, escreve Heller (2015, p. 299), o jurista havia avaliado o Estado alemão como sendo um Estado fraco, por ser um Estado pluralista, no qual certos grupos de interesses privados lutavam pelo poder. Como solução teórica, Schmitt teria recorrido ao conceito de Estado total e, portanto, forte.

Na ocasião do discurso aos industriais, teria apresentado uma interpretação mais clara do que significa Estado total para ele. O Estado total que Schmitt considera pernicioso é um que tenta ordenar a economia de forma autoritária, que é total na quantidade de tarefas que precisa realizar e, portanto, o que existiria na Alemanha durante a República de Weimar. De forma diversa, o Estado

${ }^{12}$ Cf. Wilkinson (2019). 
qualitativamente total seria o Estado total que traçaria uma linha de separação em relação à economia, embora governando, por outro lado, lançando mão de meios militares ainda mais fortes e utilizando todos os recursos de manipulação das massas, como o rádio e o cinema.

Heller (2015, p. 300) considera que o Estado Total Qualitativo advogado por Schmitt era um que tinha como objetivo principal a destruição do Estado Social. Quando os conservadores falavam em retirada do Estado da economia, não se referiam ao corte de subsídios aos grandes bancos, grandes indústrias e grandes empresas agrícolas, mas tão somente ao desmantelamento autoritário das políticas sociais. Para exemplificar, o jurista elenca falas do então presidente Franz Von Papen questionando a viabilidade da prestação pelo Estado de direitos como à saúde e à educação - previstos de modo vanguardista pela Constituição de Weimar com status de direitos fundamentais -, alegando que seriam custosos demais e que cada cidadão deveria se esforçar sozinho para ter acesso a eles (HELLER, 2015, p. 300).

Ao fim, conclui que a substância do liberalismo autoritário pode ser resumida no abandono da política social acompanhada pela liberalização da economia e do crescimento militar autoritário do Estado em todos os outros âmbitos da vida pública (HELLER, 2015, p. 301). Para Schmitt, somente um Estado autoritário poderia ser forte o suficiente para pôr fim às relações excessivas entre a política estatal e a economia. A essa alegação, Heller (2015, p. 301) responde: certamente teria que ser autoritário, porque o povo alemão jamais toleraria se esse Estado neoliberal (expressão que utiliza, devemos ressaltar, ainda em 1933) se governasse de forma democrática.

\section{A leitura de Wendy Brown sobre o paradigma neoliberal}

Exposto o debate dos juristas alemães da República de Weimar, voltemos o olhar para alguns desdobramentos do neoliberalismo no seu arranjo atual.

A filósofa norte-americana Wendy Brown, em obra intitulada Undoing the Demos: Neoliberalism's Stealth Revolution (2015), argumentou serem incompatíveis entre si a lógica política do regime liberal-democrático e o que chamou de "razão neoliberal”, uma espécie de racionalidade que estaria se instalando em todos os âmbitos da vida pública e privada e comprometendo tanto as instituições do Estado, quanto a formação da subjetividade dos sujeitos, reduzindo todos os aspectos da existência a termos econômicos.

Partindo da obra de Michel Foucault, a autora defende que o neoliberalismo provocou a "economização" das esferas sociais, de modo que os cidadãos passaram 
a se entender não como integrantes de uma comunidade de indivíduos, mas como atomizados "empresários de si próprios". Brown sustenta ainda que essa nova racionalidade foi esposada pelas instâncias estatais, de modo que passaram a gerir os bens públicos prestigiando os interesses do mercado em detrimento daqueles da coletividade, quando, não raro, se contradizem, constituindo uma espécie de "governo do econômico"13.

Alguns dos efeitos mais notáveis desse fenômeno, para a autora, são o da desnaturação dos regimes democráticos, o da atrofia dos imaginários políticos comuns e o da "vitimização fatal" do homo politicus, justamente aquele que seria, em sua forma democrática, a "principal arma” contra o avanço da racionalidade neoliberal (BROWN, 2015, p. 87).

Quatro anos depois, Wendy Brown avança nessa linha argumentativa no livro Nas ruinas do neoliberalismo (no original, In the Ruins of Neoliberalism; BROWN, 2019) ${ }^{14}$.

Na referida obra, Brown considera sob o signo "neoliberalismo” um conjunto de políticas que privilegiam a privatização de propriedades e de serviços públicos, atacam os direitos garantidos pelo Estado Social, precarizam as relações de trabalho e desregulam o capital nos mercados enquanto mantêm uma série de privilégios fiscais e alfandegários às classes empresariais. Para a autora, trata-se de um "ataque oportunista dos capitalistas e seus lacaios políticos aos Estados de bem-estar keynesianos, às sociais-democracias e ao socialismo de Estado” (BROWN, 2019, p. 29).

Brown (2019, p. 32) assinala que construiu sua análise a partir das concepções neomarxista e foucaultiana do neoliberalismo. Explica que, para o neomarxismo, o neoliberalismo é um projeto global que pretende substituir a soberania dos Estadosnações pelas regras de acordos supranacionais estabelecidos por instituições como a Organização Mundial do Comércio, o Banco Mundial e o Fundo Monetário Internacional. Essa dinâmica teria levado os países desenvolvidos do Norte a procurar mão de obra barata nos países subdesenvolvidos do Sul, o que teria aprofundado relações de desigualdade, exploração e precarização das relações de trabalho, enquanto permitido que o fluxo de capital corresse segundo os melhores interesses do mercado.

Já para a tradição foucaultiana, o neoliberalismo é a "reprogramação" do liberalismo, uma nova racionalidade política em que os princípios de mercado se tornam princípios de governo (BROWN, 2019, p. 29). O Estado é reformatado para

\footnotetext{
${ }^{13}$ No mesmo sentido, ver: Brown (2020).

${ }^{14}$ Para outras leituras sobre as reflexões formuladas por Brown, ver também: Balibar (2020); Brown (2015, 2020).
} 
servir ao capital, um fenômeno que Foucault chama de "governamentalização": "todo governo é para os mercados e orientado por princípios de mercado e, por outro lado, os mercados devem ser construídos, viabilizados, amparados e ocasionalmente até mesmo resgatados por instituições políticas” (BROWN, 2019, p. 31). No entanto, a influência dos interesses do capital não ficaria restrita às instituições estatais, pois todas as outras, como escolas, clínicas médicas, locais de trabalho de maneira geral, funcionariam também em estrita atenção aos princípios do mercado. Como resultado, o sujeito, no neoliberalismo, passa a formar sua subjetividade a partir da competição e do "aprimoramento do capital humano", diferentemente do sujeito do liberalismo clássico, que o fazia a partir da troca e da satisfação de necessidades. No neoliberalismo, o capital, desregulado, pode se instalar em todos os lugares e reorganizar o Estado, as demais instituições e a existência concreta dos sujeitos (BROWN, 2019, p. 31).

Aliando essas duas concepções, o argumento central sustentado por Brown (2019, p. 26) é o de que o neoliberalismo criou as condições necessárias para a ascensão do que chama de "política antidemocrática" no Ocidente. Em razão do aprofundamento das desigualdades e da insegurança social que promove com o desmantelamento de programas de previdência, assistência social, bem como de saúde e educação, discursos de extrema-direita, que em alguns traços lembram os discursos fascistas de 1930, ganharam força e adeptos ao redor do mundo.

O curioso, avalia Brown (2019, p. 10), é a incompatibilidade existente entre a estrutura neoliberal e o que esses discursos pregam. $\mathrm{O}$ neoliberalismo promoveu o enfraquecimento das fronteiras nacionais para privilegiar os interesses do capital transnacionalizado, mas o que a retórica de extrema-direita evoca hoje é o ultranacionalismo. O neoliberalismo demonizou a política como fonte de autoritarismo e ameaça à liberdade individual - e ao funcionamento orgânico dos mercados -, mas se verifica hoje em vários países o culto a líderes masculinos que prometem "lei e ordem”. O neoliberalismo promoveu a atomização social radical dos indivíduos, processo que prejudicou suas participações na vida pública em nome da tarefa individual de "empreender a si mesmo": como explicar, então, a emergência de polarizações políticas tão intensas e apaixonadas em volta de discursos que, em alguma medida, evocam categorias coletivas?

Para investigar essas contradições, Brown se debruça sobre a obra de alguns intelectuais neoliberais. Mas antes de começar a expor as diferenças entre eles, afirma categoricamente que nenhum advogava pelo advento de um Estado fraco. Muito pelo contrário: ao mesmo tempo em que falavam em limitar a área de atuação estatal, defendiam que, onde era obrigação do Estado agir, deveria agir com intensidade. 
Brown escreve que "os neoliberais procuravam construir, consolidar e amarrar um Estado unificado e forte, um Estado no qual a soberania política significa desunir, a democracia, desorientar e dividir, e a burocracia, exaurir” (BROWN, 2019, p. 77).

A autora expõe as cartilhas de três grandes escolas do neoliberalismo: a de Milton Friedman (Escola de Chicago), a de Friedrich Hayek (Escola Austríaca) e a dos chamados “ordoliberais”. Nós nos concentraremos sobremaneira nas considerações da autora sobre a obra de Friedrich Hayek, pela relevância que o intelectual assumiu no contexto global e pelas semelhanças que apresenta às ideias que emergiram durante a crise econômica e política da República de Weimar, já comentadas neste trabalho (BROWN, 2019).

Hayek $^{15}$, assim como os outros teóricos neoliberais, tinha como objetivo promover ideologicamente o destronamento da política, entendida como uma esfera capaz tão somente de oferecer riscos à liberdade e à organização espontânea dos mercados e da moral das sociedades. O autor distingue liberalismo e democracia (como também fez Schmitt, mas diferentemente): a democracia, para ele, é um método de governo que responde à pergunta "quem deve exercer o poder público?", enquanto o liberalismo diz respeito ao propósito e escopo do governo e responde à pergunta "independentemente de quem exerce o poder público, quais devem ser os seus limites?” (BROWN, 2019, p. 88).

A partir dessa distinção, o autor demonstraria as várias tensões entre democratas e liberais: para os integrantes do primeiro grupo, para considerar algo bom basta o fato de que seja desejado pela maioria, enquanto, para os integrantes do segundo grupo, isso não seria suficiente, na medida em que aceitam o governo da maioria tão somente como um método de decisão, mas que não é capaz de produzir juízos normativos sobre as decisões tomadas (BROWN, 2019, p. 87-88). Em resumo, Hayek, de modo semelhante ao que havia dito Schmitt anos antes, parece inferir que um liberal não necessariamente precisa ser um democrata.

As diferenças entre liberalismo e democracia também seriam verificadas pela constatação de seus opostos. Para o autor, o oposto da democracia é o autoritarismo, ou seja, a concentração de poder - não necessariamente ilimitado. Já o oposto do liberalismo é o totalitarismo, tomado como o controle total de todos os aspectos da vida pública e privada dos cidadãos. Segundo essa classificação, é possível, para Hayek, que uma sociedade liberal seja autoritária, desde que proteja a liberdade, a moral tradicional e a esfera privada, enquanto o totalitarismo pode ser imposto e 
administrado por governos democráticos. Logo, Hayek concebe como legítimo o autoritarismo utilizado como meio de transição para o liberalismo, o que o fez apoiar publicamente a ditadura violenta de Pinochet no Chile e o golpe que o empossou: combinação que Brown chama de "liberalismo autoritário" - a mesma expressão utilizada por Heller em 1933 (BROWN, 2019, p. 88-89).

Além de fundamentar teoricamente esse arranjo autoritário do liberalismo, Brown chama a atenção de que essas duas duplas de opostos geraram ainda outro argumento importante da obra de Hayek, o dos "excessos de democracia" (BROWN, 2019, p. 89). Como já dito anteriormente, o autor, como a maioria de seus pares, tinha grande desconfiança do âmbito político, com destaque para o político sob o arranjo democrático, supostamente por causa do risco do totalitarismo que ameaçaria o funcionamento orgânico tanto dos mercados quanto da moral reinante nas sociedades. No entanto, o que Hayek considera como "excessos democráticos" são, a bem da verdade, as conquistas do Estado Social, de modo que, como Brown sintetiza, "democracia em demasia significa Estado social em demasia" (BROWN, 2019, p. 89).

Para Hayek, a liberdade não éfundada pela lei ou pela política, mas pelos princípios morais que formam a tradição de um povo, os quais são obedecidos "livremente". A política, diferentemente, nega a liberdade por meio de seus mecanismos de coerção e controle (inclusive instrumentalizados por meio do direito), e a democracia, como sendo o governo da maioria, agrava ainda mais o prejuízo à liberdade e à organização espontânea da sociedade segundo sua moralidade tradicional. Aqui, percebemos como Hayek conciliou duas tendências da extrema-direita atual de modo bastante arguto: a defesa da liberdade econômica e o reforço aos valores tradicionais. Na obra de Hayek, o Estado desdemocratizado e livre da ameaça do poder ilegítimo garante, ao mesmo tempo, que a esfera moral e que a esfera econômica se desenvolvam sem intervenções estatais (BROWN, 2019, p. 91).

De modo geral, Hayek e todos os outros teóricos neoliberais rejeitaram a democracia, enquanto defenderam que poder político deveria se retirar de cena e, ao mesmo tempo, subsidiar a liberdade econômica e a ordem moral. De fato, o neoliberalismo que se impôs na realidade sufocou e rebaixou a democracia, mas os efeitos desse rebaixamento foram completamente diferentes dos pretendidos.

Brown (2019, p. 102) aponta como, em vez de isolar o grande capital das interferências do Estado, o Estado foi ocupado pelo grande capital, de modo que as grandes empresas manejam as legislações conforme seus interesses. No lugar de serem politicamente pacificados e obedientes à moralidade tradicional, os cidadãos são vulneráveis a discursos nacionalistas, ressentidos e violentos, em razão do 
aprofundamento das desigualdades sociais e da perda do acesso a serviços e bens de consumo, ocasionadas pelo desmantelamento do Estado Social.

Em curto resumo, conclui Brown que "o neoliberalismo realmente existente consiste em Estados dominados por todos os grandes interesses econômicos e compelidos a lidar com um populacho fervendo de rancor, raiva e ressentimento, para não mencionar suas necessidades materiais”, e adiciona: "Hayek imaginou uma ordem de poderes governamentais estritamente limitados e separados, ao passo que hoje os tribunais fazem leis, as legislaturas traçam políticas e o poder executivo emite 'decretos' para contornar ambos” (BROWN, 2019, p. 104).

\section{Os impasses de Weimar e os impasses atuais}

Diante do exposto, repetimos nosso questionamento inicial: como o debate entre Carl Schmitt e Hermann Heller pode contribuir para o panorama acerca do neoliberalismo desenhado por Wendy Brown?

Como explicamos no início, Carl Schmitt, um dos mais influentes juristas iliberais do século XX, elaborou uma robusta ofensiva teórica contra as instituições e institutos liberais, aqui entendidos como aqueles que funcionam no sentido da limitação do poder estatal, e desenvolveu uma teoria da democracia compatível com o autoritarismo. Diante da edificação do Estado Social pela Constituição de Weimar, Schmitt alegou que o Estado Alemão estava se transformando em um Estado Total Quantitativo, na medida em que estava se fazendo presente em todos os âmbitos da vida pública - notadamente no econômico - e, consequentemente, perdendo o monopólio do político e se tornando fraco e internamente disputado. Como solução, sugeriu a sua substituição por um modelo de Estado Total Qualitativo, segundo o qual o Estado preservaria a economia sem intervenções, enquanto intensificaria seu desempenho militar no âmbito público: em poucas palavras, esse seria um Estado forte que garantiria o livre mercado.

Hermann Heller, ao criticar a agenda teórica de seu par, nomeou-a de "liberalismo autoritário" e alegou que seu conteúdo era uma combinação do desmantelamento do Estado Social, da desregulamentação e da liberalização da economia com o autoritário agigantamento militar do Estado em todos os outros âmbitos da vida pública. Heller se refere ao Estado que abraça o liberalismo autoritário como "Estado neoliberal” e afirma que ele só poderia ser autoritário, porque, se fosse democrático, o povo jamais o toleraria. 
Wendy Brown, ao apresentar o cenário do neoliberalismo atual, argumenta que há uma contradição entre o que o neoliberalismo almejava e o que efetivamente provocou: pretendia desregulamentar os mercados e destronar a política, principalmente a democrática, mas terminou por tornar os Estados ainda mais disputados internamente e suscetíveis às influências do grande capital, ao passo em que criou condições férteis para a adesão, pelas populações, de discursos de radicais de extrema-direita que requerem um Estado forte, nacionalista e autoritário.

O que podemos concluir, comparando essa constatação com o debate dos juristas de Weimar, é que, em larga medida, esse desfecho havia sido antecipado por Schmitt e Heller: o neoliberalismo é um arranjo autoritário do liberalismo e só consegue se manter justamente pelo autoritarismo. Schmitt já advogava que a liberalização da economia deveria ser acompanhada da militarização do Estado, pois somente um Estado forte poderia manter a economia livre. Heller, percebendo criticamente esse argumento, adicionou ainda que essa liberalização seria acompanhada do desmantelamento das políticas sociais, o que levaria à perda da qualidade de vida da maior parte da população, enquanto os privilégios dos grandes empresários seriam mantidos ou mesmo multiplicados.

Carl Schmitt, em conformidade com os neoliberais, a exemplo de Friedrich Hayek, associou democracia a Estado Social e considerou ambos nocivos à existência forte do Estado. Por essa razão, viu com bons olhos regimes ditatoriais, que conseguiriam manter a unidade do Estado e se colocar acima das disputas em sociedade. Hayek pensou o mesmo, embora partindo de um raciocínio diverso. $\mathrm{O}$ neoliberalismo, no entanto, quando prestigiado por regimes pelo menos virtualmente democráticos, gera os efeitos descritos por Brown, tais como a ascensão de discursos extremistas que pedem justamente por autoritarismo. Em uma palavra, Heller parece ter acertado em seu diagnóstico.

\section{Conclusão}

Em suma, podemos concluir, antes de mais nada, que a experiência-limite da República de Weimar e as discussões que se deram nesse contexto têm muito a dizer sobre os entrecruzamentos contemporâneos relativos a política, economia e formatação do Estado. 
O debate entre Carl Schmitt e Hermann Heller antecipou em pelo menos quarenta anos uma série de discussões sobre o (neo)liberalismo e nos ajuda a entender a configuração que este tomou atualmente. Como Wendy Brown argumenta em Nas ruínas do neoliberalismo, o projeto neoliberal, exceto pelo bemsucedido sufocamento da democracia, parece ter fracassado. Intencionando um Estado não intervencionista, mas que garantisse a solubilidade do mercado, acabou criando um Estado manipulado pelos interesses do capital e suscetível a disputas de interesses econômicos dentro de suas próprias estruturas. Quanto à sociedade civil, almejava indivíduos pacíficos e ordeiros que simplesmente observassem a ordem moral "livremente" e de modo espontâneo, mas o que se verifica hoje é a ascensão de discursos de extrema-direita que evocam nacionalismo, autoritarismo e são mobilizados por afetos como raiva, indiferença e ressentimento.

A razão desse descompasso entre as expectativas e a realidade está no diagnóstico acerca do neoliberalismo realizado por Hermann Heller: o neoliberalismo é um liberalismo autoritário que, em virtude da precarização das relações em sociedade e do desmonte das políticas sociais, só pode ser suportado pelo povo se este for obrigado a tanto, ou seja, se sua faceta política for autoritária. Por essa razão, a fragilização da democracia que o neoliberalismo causou (ou a promoção do que Brown chamou de "cultura política antidemocrática") parece agora apresentar como resultado uma evocação ao autoritarismo que, para Heller, seria imprescindível para a subsistência do projeto neoliberal. O fracasso da República de Weimar levou à ascensão do III Reich e do regime nazifascista de Adolf Hitler: já se sabe que as investidas contra o Estado Social e contra a democracia podem operar verdadeiras barbáries humanitárias, precisamente porque vêm acompanhadas de discursos disruptivos, nacionalistas e violentos. No caso da presente fase do neoliberalismo, esses discursos, embora tenham demorado um certo período para ganhar adesão, agora já estão na ordem do dia e oferecendo ameaças graves e concretas à garantia dos direitos individuais, direitos sociais e à forma democrática de governo, de modo que é imprescindível voltar o olhar para os momentos históricos que já anunciavam essas questões, para impedir que as tragédias se repitam. 


\section{Referências}

BALIBAR, Étienne. Absolute capitalism. In: CALLISON, William; MANFREDI, Zachary (ed.). Market rule and political rupture. Fordham University Press: Nova York, 2020.

BERCOVICI, Gilberto (coord.). Cem anos da Constituição de Weimar (1919-2019). São Paulo: Quartier Latin, 2019.

BERCOVICI, Gilberto. Entre o estado total e o estado social: atualidade do debate sobre direito, estado e economia na República de Weimar. 2003. Tese (Livre Docência em Direito Econômico) - Faculdade de Direito, Universidade de São Paulo, São Paulo, 2003. Disponível em: doi:10.11606/T.2.2009.tde-22092009-150501. Acesso em: 3 nov. 2020.

BIELEFELDT, Heiner. Carl Schmitt's critique of liberalism: systematic reconstruction and countercriticism. In: DYZENHAUS, David. Law as politics: Carl Schmitt's critique of liberalism. Durham: Duke University Press, 1998.

BROWN, Wendy. Nas ruínas do neoliberalismo: a ascensão da política antidemocrática no ocidente. Tradução de Mario A. Marino, Eduardo Altheman C. Santos. São Paulo: Editora Filosófica Politeia, 2019.

BROWN, Wendy. Neoliberalism's scorpion tail. In: CALLISON, William; MANFREDI, Zachary (ed.). Market rule and political rupture. Fordham University Press: Nova York, 2020.

BROWN, Wendy. Undoing the demos: neoliberalism's stealth revolution. Nova York: Zone Books, 2015.

BUENO, Roberto. Antiliberalismo e conservadorismo teológico: de Donoso Cortés a Carl Schmitt. In: BUENO, Roberto; RAMIRO, Caio Henrique Lopes (orgs.). Sonhos e pesadelos da democracia em Weimar: tensões entre Carl Schmitt e Hans Kelsen. São Paulo: LiberArts, 2017.

DYZENHAUS, David. Law as politics: Carl Schmitt's critique of liberalism. Durham: Duke University Press, 1998.

EBERL, Oliver; SALOMON, David. Crítica ao parlamentarismo e à democracia social na República de Weimar: Carl Schmitt e o atual debate pós democrático. In: BERCOVICI, Gilberto (coord.) Cem anos da Constituição de Weimar (1919-2019). São Paulo: Quartier Latin, 2019.

FERREIRA, Bernardo. "O mais claro suicídio da história constitucional”: Carl Schmitt confronta a Constituição de Weimar. In: BERCOVICI, Gilberto (coord.). Cem anos da Constituição de Weimar (1919-2019). São Paulo: Quartier Latin, 2019.

HAYEK, Friedrich. Arrogância fatal: os erros do socialismo. Tradução de Anna Maria Capovilla, Candido M. Prunes. São Paulo: Ortiz, 1995. 
HAYEK, Friedrich. The Constitution of liberty. Chicago: University of Chicago Press, 1960.

HAYEK, Friedrich. Direito, legislação e liberdade: uma nova formulação dos princípios liberais de justiça e economia política. Tradução de Anna Maria Copovilla et al. São Paulo: Visão, 1985.

HAYEK, Friedrich. The fatal conceit: the errors of socialism. Chicago: University of Chicago Press, 1989.

HAYEK, Friedrich. Os fundamentos da liberdade. Tradução de Anna Maria Copovilla, José Italo Stelle. São Paulo: Visão, 1983.

HAYEK, Friedrich. Law, legislation, and liberty. Chicago: University of Chicago Press, $1973.3 \mathrm{v}$.

HAYEK, Friedrich. Professor Friedrich Hayeks's closing speech. Mont Pelerin, Paris, 3 Mar. 1984. Conservatism: Hayek speech to the Mont Pelerin Society: reflections on the history of the society and the resurgence of classical liberalism. Disponível em: https://www. margaretthatcher.org/document/117193. Acesso em: 23 abr. 2021.

HELLER, Hermann. Authoritarian liberalism? European Law Journal, v. 21, n. 3, p. 295-301, maio 2015.

LEYDET, Dominique. Pluralism and the crisis of parlamentary democracy. In: DYZENHAUS, David. Law as politics: Carl Schmitt's critique of liberalism. Durham: Duke University Press, 1998.

MARTÍN, Sebastián. Los fundamentos sociales, políticos y jurídicos del Soziale Rechsstaat: oportunidad actual de Hermann Heller (1891-1993). In: BERCOVICI, Gilberto (coord). Cem anos da Constituição de Weimar (1919-2019). São Paulo: Quartier Latin, 2019.

MARTINS, Argemiro Cardoso Moreira. O pensamento político-constitucional de Carl Schmitt no contexto histórico-político da república de Weimar. 1996. Dissertação (Mestrado em Direito), Centro de Ciências Jurídicas - Universidade Federal de Santa Catarina. Florianópolis, 1996.

MOUFFE, Chantal. Carl Schmitt and the paradox of liberal democracy. In: MOUFFE, Chantal (ed.). The challenge of Carl Schmitt. Londres: Verso, 1999.

NUNES, António José Avelãs Nunes. A república de Weimar e a Constituição de Weimar, cem anos depois. In: BERCOVICI, Gilberto (coord.) Cem anos da Constituição de Weimar (1919-2019). São Paulo: Quartier Latin, 2019.

PREUSS, Ulrich K. Political order and democracy: Carl Schmitt and his influence. In: MOUFFE, Chantal (ed.). The challenge of Carl Schmitt. Londres: Verso, 1999. 
SCHEUERMAN, William. The end of law: Carl Schmitt in the twenty-first century. Londres: Rowman \& Littlefield International, 2020.

SCHMITT, Carl. Staat, grossraum, nomos: Arbeiten aus den Jahren 1916-1969. Berlim: Dunker \& Humblot, 1995.

SCHMITT, Carl. A crise da democracia parlamentar. Tradução de Inês Lohbauer. São Paulo: Scritta, 1996a.

SCHMITT, Carl. Teoria de la Constituicíon. Tradução de Francisco Ayala. Madri: Alianza Editorial, 1996b.

SCHMITT, Carl. O guardião da Constituição. Tradução de Geraldo de Carvalho. Belo Horizonte: Editora Del Rey, 2007.

SEITZER, Jeffrey. Carl Schmitt's internal critique of liberal constitutionalism: Verfassungslehre as a response to the Weimar State crisis. In: DYZENHAUS, David (ed.). Law as politics: Carl Schmitt's critique of liberalism. Durham: Duke University Press, 1998.

VERBICARO, Loiane Prado. Reflexões acerca das contradições entre democracia e neoliberalismo. Revista de Direito Público. Brasília, Volume 18, n. 97, 23-51, jan./fev. 2021. Disponível em: https://www.portaldeperiodicos.idp.edu.br/direitopublico/article/ view/5115. Acesso em: 24 jun. 2021.

WILKINSON, Michael A. Authoritarian liberalism as authoritarian constitutionalism. LSE Legal Studies Working Paper, n. 18, Nov. 2018. Disponível em: https://ssrn.com/ abstract $=3281320$. Acesso em: 23 abr. 2021. 